\title{
Increasing incidence of childhood leukaemia: a controversy re-examined
}

\author{
A Shah",I and MP Coleman' \\ 'Non-communicable Disease Epidemiology Unit, Department of Epidemiology and Population Health, London School of Hygiene and Tropical Medicine, \\ Keppel Street, London WCIE 7HT, UK
}

We provide evidence of a gradual increase in the incidence of childhood leukaemia over the twentieth century from examination of trends in both incidence and mortality in England and Wales. We conclude that much of the recorded increase is likely to be real. British Journal of Cancer (2007) 97, 1009-1012. doi:I0.1038/sj.bjc.6603946 www.bjcancer.com

Published online 2I August 2007

(c) 2007 Cancer Research UK

Keywords: childhood leukaemia; incidence; mortality; trends

In Europe, childhood lymphoid leukaemia incidence (including acute lymphoblastic leukaemia (ALL)) increased significantly by an average of $1.4 \%$ per year during $1970-1999$ (Steliarova-Foucher et al, 2004). In England and Wales, the increase in ALL has been attributed to the 'common' precursor B-cell subtype (Feltbower et al, 2001; Kroll et al, 2006). Debate has arisen over whether the increase is artefactual (Leukaemia Research Fund, 2004; Adamson et al, 2005) or real (Steliarova-Foucher et al, 2004, 2005).

Fewer than 5\% of children diagnosed with leukaemia in England before the early 1960s survived more than 5 years after diagnosis (Thames Cancer Registry, 1994), and mortality trends before 1960 may thus be considered a reasonable proxy for incidence. We have therefore examined all the available data on incidence and mortality trends for childhood leukaemia in England and Wales over most of the twentieth century.

Leukaemia is the commonest cancer in children (0-14 years), representing a third of all malignancies (Parkin et al, 1998). Incidence rates increase to a peak around age 3-4 years and then decline (Swerdlow et al, 2001). Some 400 children are diagnosed in England and Wales each year, and about 100 die of it. Four out of five cases of leukaemia in children are ALL, and the remaining almost all acute myeloid leukaemia (AML).

\section{MATERIALS AND METHODS}

Data on childhood leukaemia incidence and mortality in England and Wales up to the year 2000 were used to examine trends by age (under 1 year, and 1-4,5-9,10-14 years), sex and 5-year period. Mortality data for 1911-2000 and incidence data for 1971-1990 were obtained from the Office for National Statistics (ONS) (Office for National Statistics, 1998, 2003). Additional cancer registration data for the period 1991-2000 were obtained separately from ONS. Annual incidence and mortality rates for children aged 0-14 years were adjusted to the world standard population (Parkin et al, 1992). Variance-weighted least-squares linear regression was used

*Correspondence: Dr A Shah; E-mail: anjali.shah@Ishtm.ac.uk Received 27 April 2007; revised 27 July 2007; accepted 30 July 2007; published online 2I August 2007 to estimate the average quinquennial change in incidence and mortality rates.

Mortality data held by ONS span the whole of the twentieth century. Before 1959, however, the only data available are those published in the Registrar General's Annual Reviews. Computerised information on individual deaths has only been available since 1959. These data have been published on CD-ROM (Office for National Statistics, 2003).

Death registrations derived from medical certificates of cause of death are coded at ONS to the World Health Organisation's (WHO) International Classification of Diseases (ICD). The ICD underwent 10 revisions during the twentieth century, reflecting successive advances in medical knowledge and disease classification. The first version, in force during 1901-1910, did not include a separate category for leukaemia, so it is impossible to estimate national mortality rates for childhood leukaemia before 1911. The ICD codes for leukaemia data used in the analyses are given in Table 1.

The ONS has coordinated cancer registration nationally in England and Wales since 1971 through a network of populationbased regional cancer registries in England and a national cancer registry in Wales (Office for National Statistics, 2004a).

\section{RESULTS}

Childhood leukaemia mortality rates increased four-fold from 8.4 per million person-years in $1911-1915$ to reach 34.7 by the late 1950s (Figure 1). The decline in mortality over the second half of the twentieth century to 10.3 per million person-years has been similarly impressive.

Leukaemia mortality peaked earlier for children under 5 years of age (1941 - 1955) than for older children (1956-1970). The 5-yearly decline in childhood leukaemia mortality was significant for each age group over the period 1971-2000. Peak mortality varied widely by age, from 23.4 per million for children aged $10-14$ years to 51.8 at ages 1-4 years (Table 2). The increase and almost symmetric decrease in mortality is particularly marked in children aged 1-4 years, with a peak of 51.8 deaths per million person-years during $1951-1955$, declining by $80 \%$ to 10.6 by $1996-2000$. 
Incidence rose by $20 \%$ between the early 1970 s and the end of the century (Figure 1), an increase of $4 \%$ every 5 years. Both incidence and mortality were at least $15 \%$ higher in boys than girls throughout the twentieth century. Incidence at ages $1-4$ years was more than double that of any other age group (Table 3 ). The average 5-yearly increase in incidence over the period 1971-2000 was significant in all age groups, but the overall increase was much larger among children under 5 years ( $46 \%$ in infants, $24 \%$ in children aged $1-4$ years) than in older children $(12-15 \%)$.

\section{DISCUSSION}

The divergence between rising incidence and falling mortality is remarkable, but it reflects the great improvement in 5-year survival, from less than $5 \%$ in the early 1960s (Thames Cancer Registry, 1994) to almost $80 \%$ by the end of the 1990 s (Coleman et al, 1999; Shah, 2005). Since survival was so low before the early 1960 s, it seems likely that mortality from 1911 up to the 1950 s provides a reasonable proxy for incidence trends. Taken together with the directly observed incidence trends from the 1970s to the late 1990s, these data strongly suggest a century-long increase in childhood leukaemia, particularly in children under 5 years of age.

Similar trends for childhood leukaemia have been observed in the United States, with an increase in mortality until the 1960s. The

Table I International classification of disease codes for leukaemia

\begin{tabular}{ccccc}
\hline ICD revision & Mortality & $\begin{array}{c}\text { Period in use } \\
\text { for mortality }\end{array}$ & Incidence & $\begin{array}{c}\text { Period in use } \\
\text { for incidence }\end{array}$ \\
\hline 2 & $53 \mathrm{~A}$ & $1911-1920$ & - & \\
3 & $65 \mathrm{~A}$ & $1921-1930$ & - & \\
4 & $72 \mathrm{~A}$ & $1931-1939$ & - & \\
5 & $72 \mathrm{~B}$ & $1935-1939$ & - & \\
6 & $74 \mathrm{~A}$ and $74 \mathrm{~B}$ & $1940-1949$ & - & \\
7 & 204 & $1950-1957$ & - & \\
8 & 204 & $1958-1967$ & - & $1971-1978$ \\
9 & $204-207$ & $1968-1978$ & $204-207$ & $1979-1994$ \\
10 & $204-208$ & $1979-2000$ & $204-208$ & $1995-2000$ \\
\hline
\end{tabular}

subsequent decline in mortality, resulting from improvements in treatment, has been seen world-wide (Fraumeni and Miller, 1967; Coleman et al, 1993; Smith et al, 1999). Incidence has increased significantly in Europe and in the United States since the 1970s, which is essentially attributable to ALL (Coleman et al, 1993; Smith et al, 1999; Xie et al, 2003; Steliarova-Foucher et al, 2004). However, the incidence of ALL and AML has been stable in the Nordic countries between 1982 and 2001 (Hjalgrim et al, 2003).

The childhood peak at 2-4 years that began to develop in the 1920s in England and Wales developed later in other nations, for example in the 1940s in US Caucasians and in the 1960s in Japan and in US non-Caucasians, but it has not been seen in some developing countries (Fraumeni and Miller, 1967; Greaves et al, 1985). Differences in leukaemia incidence, most apparent at ages 2-3 years, have been observed between Caucasian and AfricanAmerican children in the United States, and between children in western and eastern Europe (Doll, 1989; Smith et al, 1999; Steliarova-Foucher et al, 2004). The development of this age peak is the main component of the overall increase in leukaemia incidence in England and Wales and other countries over the twentieth century.

The cause of childhood leukaemia remains unknown. It has been suggested that a leukaemic exposure arose in developed countries in the early part of the twentieth century possibly associated with improved living standards (Doll, 1989). Although improvements in case-finding and in the accuracy of death certification in England and Wales are considered to have had an impact on childhood leukaemia mortality, particularly during the early part of the century, the continued increase in mortality into, and beyond, the 1950s indicates a real increase in incidence (Court Brown and Doll, 1961; Doll, 1989; Swerdlow et al, 2001). More complete ascertainment by cancer registries has also been proposed (Adamson et al, 2005), and while this may have had some impact in the early 1970s, under-ascertainment of childhood cancers has been estimated at less than 5\% during 1971-1984 (Hawkins and Swerdlow, 1992). It also seems implausible that any systematic underreporting of leukaemia would have been restricted to children under 5 years, and particularly to those with the precursor B-cell subtype of ALL.

It has been hypothesised that, in the first few decades of the twentieth century, a fatal infection (e.g. pneumonia) attributable to pre-leukaemic immunosuppression would have killed a proportion

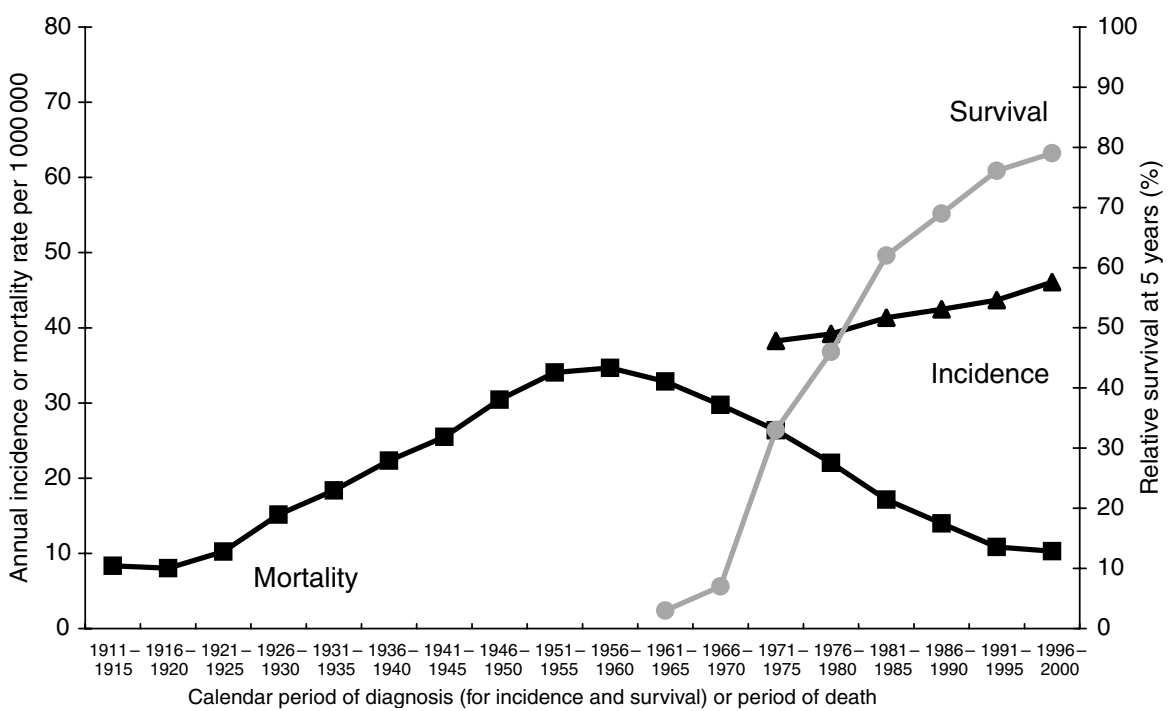

Figure I Trends in leukaemia incidence, survival and mortality in children ( $0-14$ years), England and Wales, $191 \mid-2000$. Incidence and mortality rates per million person-years for England and Wales (Office for National Statistics, 1998, 2003). Five-year relative survival rates (\%) for children diagnosed in South-East England 1960-1970 (Thames Cancer Registry, 1994), in England and Wales during 197I - 1990 (Coleman et al, 1999) and in Great Britain 199|-2000 (Shah, 2005). 
Table 2 Childhood leukaemia mortality rate per million person-years by sex and age, England and Wales, |9|1-2000

\begin{tabular}{|c|c|c|c|c|c|c|c|c|c|c|c|c|c|c|c|c|c|c|c|c|}
\hline & \multicolumn{18}{|c|}{ Period of death } & \multicolumn{2}{|c|}{$\begin{array}{c}\text { Average } \\
\text { quinquennial } \\
\text { change } \\
(1971-2000)\end{array}$} \\
\hline & $\begin{array}{c}1911- \\
1915\end{array}$ & $\begin{array}{c}1916- \\
1920\end{array}$ & $\begin{array}{c}1921- \\
1925\end{array}$ & $\begin{array}{c}1926- \\
1930\end{array}$ & $\begin{array}{c}1931- \\
1935\end{array}$ & $\begin{array}{c}1936- \\
1940\end{array}$ & $\begin{array}{c}1941- \\
1945\end{array}$ & $\begin{array}{c}1946- \\
1950\end{array}$ & $\begin{array}{c}1951- \\
1955\end{array}$ & $\begin{array}{c}1956- \\
1960\end{array}$ & $\begin{array}{c}1961- \\
1965\end{array}$ & $\begin{array}{c}1966- \\
1970\end{array}$ & $\begin{array}{c}1971- \\
1975\end{array}$ & $\begin{array}{c}1976- \\
1980\end{array}$ & $\begin{array}{c}1981- \\
1985\end{array}$ & $\begin{array}{c}1986- \\
1990\end{array}$ & $\begin{array}{c}1991- \\
1995\end{array}$ & $\begin{array}{c}1996- \\
2000\end{array}$ & $\begin{array}{c}\text { Time } \\
\text { trend }^{\mathrm{a}}\end{array}$ & $\begin{array}{c}95 \% \\
\text { confidence } \\
\text { interval }\end{array}$ \\
\hline All & 8.4 & 8.0 & 10.2 & 15.2 & 18.4 & 22.3 & 25.5 & 30.4 & 34.1 & 34.7 & 32.9 & 29.7 & 26.4 & 22.0 & 17.1 & 14.0 & 10.9 & 10.3 & -3.8 & $-3.8-3.8$ \\
\hline \multicolumn{21}{|l|}{ Sex } \\
\hline Male & 10.3 & 9.8 & 12.5 & 18.0 & 20.4 & 26.0 & 30.4 & 33.6 & 37.0 & 38.3 & 36.1 & 32.4 & 29.3 & 26.8 & 19.6 & 15.4 & 13.5 & 11.6 & -3.9 & $-3.9-3.9$ \\
\hline Female & 6.4 & 6.2 & 8.0 & 12.3 & 16.3 & 19.2 & 20.5 & 27.2 & 31.9 & 30.9 & 29.4 & 27.0 & 23.3 & 17.0 & 14.6 & 12.6 & 8.1 & 8.9 & -3.2 & $-3.2-3.2$ \\
\hline \multicolumn{21}{|l|}{ Age (years) } \\
\hline$<1$ & 9.9 & 10.8 & 11.6 & 17.4 & 19.7 & 28.4 & 29.4 & 25.1 & 29.0 & 23.2 & 24.8 & 19.4 & 18.8 & 13.8 & 12.7 & 8.9 & 9.5 & 6.4 & -2.2 & $-3.0-1.3$ \\
\hline $1-4$ & 11.5 & 10.2 & 13.4 & 21.9 & 25.5 & 33.6 & 36.0 & 46.8 & 51.8 & 48.5 & 43.8 & 37.9 & 30.6 & 21.7 & 16.4 & 4.8 & 9.4 & 10.6 & -3.7 & $-4.2-3.1$ \\
\hline $5-9$ & 7.5 & 7.0 & 9.5 & 12.6 & 16.2 & 18.4 & 22.1 & 26.3 & 29.7 & 35.6 & 34.7 & 30.2 & 30.9 & 27.2 & 18.7 & 13.6 & 12.2 & 10.0 & -4.1 & $-4.6-3.7$ \\
\hline $10-14$ & 5.5 & 6.1 & 7.3 & 10.3 & 12.8 & 13.0 & 17.2 & 19.1 & 21.3 & 22.0 & 21.3 & 23.4 & 18.9 & 18.9 & 17.4 & 15.0 & 11.2 & 11.3 & -1.8 & $-2.3-1.4$ \\
\hline
\end{tabular}

${ }^{a}$ Average quinquennial change in the mortality rate per million person-years between 1971 - 1975 and 1996-2000. Mortality rates are age-standardised to the world standard population.

Table 3 Childhood leukaemia incidence rate per million person-years by sex and age, England and Wales, 197I -2000

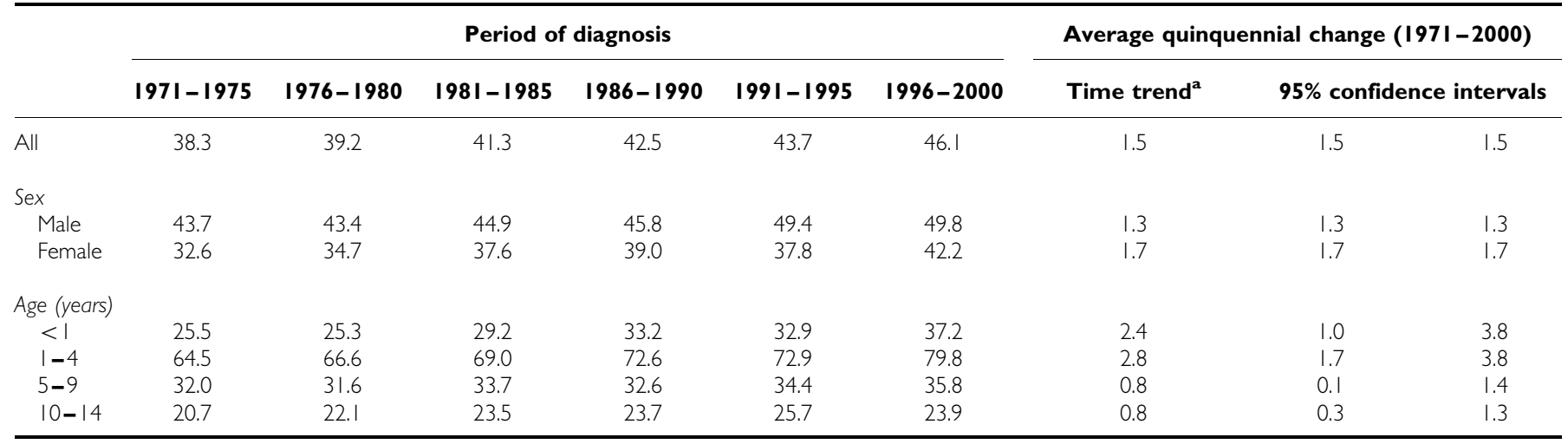

${ }^{a}$ Average quinquennial change in the incidence rate per million person-years between 1971 - 1975 and 1996-2000. Incidence rates are age-standardised to the world standard population.

of children before the leukaemia became obvious. After the introduction of antibiotics, the effect of fatal infections in 'masking' leukaemia would have declined, leading to the observed increase in leukaemia incidence (Stewart and Kneale, 1969). A state-wide study in Colorado during 1941-1959, however, concluded that the severity and often fatal outcome of childhood leukaemia would usually have resulted in hospitalisation, and that few cases would have remained undiagnosed there (Githens et al, 1965).

Even if fatal infections may have had some impact on 'masking' leukaemia during the first half of the century, their involvement cannot explain the increase in incidence of childhood leukaemia during 1971-2000. Infant mortality (in the first year of life) fell from 18 in 1971 to 6 per thousand live births in 2000 (ONS, 2004b). If all other causes of death up to age 5 years are ignored, this would allow some 12000 children per million live births (18 minus 6 per 1000 ) each year to reach age 5 years who would not previously have done so. Leukaemia incidence in children aged 1-4 years increased from 64.5 per million person-years during 1971-1975 to 79.8 during 1996-2000, an increase of 15.3 cases per million. The incidence of leukaemia in the 12000 'extra' children per million per year who would previously have died in infancy would have to have been 1275 per million person-years, some 20 times higher than in the rest of the population, in order for the overall decline in infant mortality in the period 1971-2000 to account for the overall increase in leukaemia incidence.

In 1940, the WHO rule for selecting the underlying cause when more than one cause is mentioned on the death certificate changed, with the introduction of ICD-5: this resulted in a $3 \%$ reduction in leukaemia mortality at all ages (Swerdlow et al, 2001). Similarly, aleukaemia, previously defined as lymphadenoma or agranulocytosis, was included with leukaemia from 1950 (ICD-6). These shifts would have caused small changes in the number of childhood deaths coded to leukaemia, but cannot explain the increase over a period of 40 years.

The above explanations seem unlikely to explain fully the longterm changes in mortality and incidence, particularly since the disparities in trends between girls and boys have been broadly consistent over the century. We are forced to conclude that the increase in incidence is largely real.

\section{ACKNOWLEDGEMENTS}

We thank members of the Office for National Statistics, in particular Helen Wood, for access to the National Cancer Registry, mortality data and population denominators that ONS has 
maintained at such high quality for so many years. We also thank members of the UK Association of Cancer Registries who collect the original cancer patient data for collation by the National
Cancer Registry at the Office for National Statistics. We thank Children with Leukaemia for funding this research, in particular Alasdair Philips for initiating this study.

\section{REFERENCES}

Adamson P, Law G, Roman E (2005) Assessment of trends in childhood cancer incidence. Lancet 365: 753

Coleman MP, Babb P, Damiecki P, Grosclaude PC, Honjo S, Jones J, Knerer G, Pitard A, Quinn MJ, Sloggett A, de Stavola BL (1999) Cancer Survival Trends in England and Wales 1971 -1995: Deprivation and NHS Region. Series SMPS No. 61 pp 588-589. London: The Stationery Office

Coleman MP, Estève J, Damiecki P, Arslan A, Renard H (1993) Trends in Cancer Incidence and Mortality (IARC Scientific Publications No. 121) pp 1-806. Lyon: International Agency for Research on Cancer

Court Brown WM, Doll R (1961) Leukaemia in childhood and young adult life: trends in mortality in relation to aetiology. BMJ 2: $981-988$

Doll R (1989) The epidemiology of childhood leukaemia. J R Stat Soc Ser A Stat Soc 152: $341-351$

Feltbower RG, Moorman AV, Dovey G, Kinsey SE, McKinney PA (2001) Incidence of childhood acute lymphoblastic leukaemia in Yorkshire, UK. Lancet 258: $385-387$

Fraumeni Jr JF, Miller RW (1967) Epidemiology of human leukaemia: recent observations. J Natl Cancer Inst 38: 593-605

Githens JH, Elliot FE, Saunders LH (1965) The relation of socioeconomic factors to incidence of childhood leukaemia. Public Health Rep 80: $573-578$

Greaves MF, Pegram SM, Chan LC (1985) Collaborative group study of the epidemiology of acute lymphoblastic leukaemia subtypes: background and first report. Leuk Res 9: 715-733

Hawkins MM, Swerdlow A (1992) Completeness of cancer and death follow-up obtained through the National Health Service Central Register for England and Wales. Br J Cancer 66: 408-413

Hjalgrim LL, Rostgaard K, Schmiegelow K, Soderhall S, Kolmannskog S, Vettenranta K, Kristinsson J, Clausen N, Melbye M, Hjalgrim $\mathrm{H}$ Gustafsson G (2003) Age- and sex-specific incidence of childhood leukaemia by immunophenotype in the Nordic countries. J Natl Cancer Inst 95: 1539 - 1544

Kroll ME, Draper GJ, Stiller CA, Murphy MF (2006) Childhood leukaemia incidence in Britain, 1974-2000: time trends and possible relation to influenza epidemics. J Natl Cancer Inst 98: 417-420

Leukaemia Research Fund press release (2004) (3 September 2004) Comment on childhood leukaemia incidence

Office for National Statistics (1998) Cancer 1971-1997 (CDROM). London: Office for National Statistics

Office for National Statistics (2003) Twentieth Century Mortality (England and Wales, 1911-2000) (CDROM). London: The Stationery Office
Office for National Statistics (2004a) Cancer Statistics. Registrations: England and Wales, 2001 pp 4-10. London: The Stationery Office Series MB1 No. 32

Office for National Statistics (2004b) Mortality Statistics: General, England and Wales, 2002. Series DH1 No.35 p 4. London: The Stationery Office

Parkin DM, Kramárová E, Draper GJ, Masuyer E, Michaelis J, Neglia J, Qureshi S, Stiller CA (1998) In: International Incidence of Childhood Cancer, volume II (IARC Scientific Publications No. 144), (eds) p 366. Lyon: International Agency for Research on Cancer

Parkin DM, Muir CS, Whelan SL, Gao Y-T, Ferlay J, Powell J (1992) In: Cancer Incidence in Five Continents, Volume VI (IARC Scientific Publications No. 120), (eds) pp 865-870. Lyon: International Agency for Research on Cancer

Shah A (2005) Childhood leukaemia in Great Britain: trends in incidence, survival and 'cure'. PhD Thesis, London School of Hygiene and Tropical Medicine. p 134

Smith MA, Gloeckler Ries LA, Gurney JG, Ross JA (1999) Leukemia. In: Ries LAG, Smith MA, Gurney JG, Linet M, Tamra T, Young JL, Bunin GR (eds) Cancer Incidence and Survival Among Children and Adolescents: United States SEER Program 1975-1995. Bethesda, MD: National Cancer Institute, SEER Program

Steliarova-Foucher E, Stiller C, Kaatsch P, Berrino F, Coebergh JWW (2005) Trends in childhood cancer incidence in Europe, 1970-99. Lancet 365: 2088

Steliarova-Foucher E, Stiller CA, Kaatsch P, Berrino F, Coebergh JWW, Lacour B, Parkin M (2004) Geographical patterns and time trends of cancer incidence and survival among children and adolescents in Europe since the 1970s (the ACCIS project): an epidemiological study. Lancet 364: $2097-2105$

Stewart A, Kneale GW (1969) Role of local infections in the recognition of haemopoietic neoplasms. Nature 223: $741-742$

Swerdlow AJ, dos Santos Silva I, Doll R (2001) Cancer Incidence and Mortality in England and Wales: Trends and Risk Factors. pp 181-193. Oxford: Oxford University Press

Thames Cancer Registry (1994) Cancer in South East England, 1991: Cancer Incidence, Prevalence and Survival in Residents of the District Health Authorities in South East England. p 43. Sutton: Thames Cancer Registry

Xie Y, Davies SM, Xiang Y, Robison LL, Ross JA (2003) Trends in leukaemia incidence and survival in the United States (1973-1998). Cancer 97: 2229-2235 